\title{
The Effects of Green Accounting in the Society
}

\author{
Hossein Yarahmadi ${ }^{1, *}$, Ali Bohloli \\ ${ }^{1}$ City Tax Office of Doroud, Iran and the Department of Accounting at the Payam Noor University, Doroud, Iran \\ ${ }^{2}$ Tax Administration of Dorud city, Doroud, Iran
}

Email address:

Ho_yar40@yahoo.com (H. Yarahmadi)

\section{To cite this article:}

Hossein Yarahmadi, Ali Bohloli. The Effects of Green Accounting in the Society. Journal of Finance and Accounting. Vol. 3, No. 5, 2015, pp. 140-149. doi: 10.11648/j.jfa.20150305.15

\begin{abstract}
In today's global economy, organizations are increasingly called upon to demonstrate sound business management that includes concern for economic, social and environmental issues. The challenges created by global competition make it imperative for enterprises to continually rationalize and improve all resources and processes. Separation of responsibilities for the processes that underpin organizational outputs is unsustainable in today's competitive environment. On the base of literature review, we assert that recent achievements proved that ISO's management system standards have a global relevance of and a capacity to benefit from the very largest to the very smallest organizations in both public and private sectors. An Environmental Management System (EMS) provides a solid framework for meeting environmental challenges and realizing the above benefits. Most environmental legislation now originates at the European level, where the main legal instruments are EU directives and regulations. Traditionally, environmental regulation has covered the environmental media. From the early 1990s, a more integrated approach has been taken across all media with Integrated Pollution Control (IPC) and, more recently, the Integrated Pollution Prevention and Control (IPPC) European Directive. We describe in our research the main types of environmental standards used across Europe and their impact on businesses performance. In conclusion we analyse the future key areas the environmental legislation is likely to be developed in.
\end{abstract}

Keywords: Green Accounting, Environmental Management Systems, Environmental Statements, Environmental Performance

\section{Introduction}

Sustainable development policy and practice have attracted considerable attention and debate in the past 20 years. Our understanding of and concerns about environmental and sustainable development issues have evolved over time too. Evidence suggests that a focus on the triple bottom line: economic, social and environmental issues results in advantages in financing, insurance, marketing, regulatory treatment, and other areas. Business today is not just about selling a product or service to a customer around the corner. In the rapid evolution to a global market-place, having a set of common rules is critical to facilitating trade. At the same time, these rules have to be flexible enough to be applicable to companies all over the world.

Increasingly in this single world market, an organization needs to be able to demonstrate sound business management that includes concern for the environment. Recent achievements proved that ISO's management system standards have a global relevance of and a capacity to benefit from the very largest to the very smallest organizations in both public and private sectors.

An Environmental Management System (EMS) is a structured approach to addressing the environmental bottom line. Businesses recognize that a focus on "command and control" by itself does not provide the bottom line results desired. An EMS provides a solid framework for meeting environmental challenges and realizing the above benefits.

A management system comprises several "layers" (enterprise functions), such as research, development, production, sales, marketing, maintenance, service, personnel, budgeting, investment, etc. The performance of each layer is determined by "factors" such as customer and supplier relations, personnel qualification and motivation or human relations (ISO, 2002).

The challenges created by global competition make it imperative for enterprises to continually rationalize and improve all resources and processes. Separation of responsibilities for the processes that underpin 
organizational outputs is unsustainable in today's competitive environment (Guertler, 2001).

\section{The Approach: Incorporating Nature's Assets}

Figure 1 illustrates how the SEEA introduces nature's environmental and economic assets and the 'environmental cost' of their degradation and depletion into the System of National Accounts (SNA). The asset accounts measure the value of opening and closing stocks of economic and environmental assets, and their changes during an accounting period. Changes in assets are brought about by the formation and consumption of produced and natural capital (assets) and other non-economic influences such as discoveries, natural disasters or natural regeneration. The latter, i.e. 'other asset changes,' are recorded outside the income and production accounts; these changes do not, therefore, affect the conventional indicators of cost, income, product and capital formation.

\section{Aggregation and Valuation}

National environmental accounting requires adding up inputs, outputs and environmental impacts, and combining them into environmentally adjusted ('greened') indicators. The SEEA uses both monetary values (prices, costs) and physical weights (in particular the mass of material flows) to this end.

Environmentalists criticize the use of market values for 'pricing the priceless' categories of nature. In their view, assessing environmental assets and their services in monetary terms 'commodifies' nature, whose intrinsic value should not be subjected to market preferences. They prefer measuring environmental impacts by physical indicators and aggregating material flows through the economy ('throughput') in material flow accounts. However, weighting nature by the weight of materials and pollutants assigns doubtful significance (in tonnes) to diverse environmental impacts such as the depletion of a timber tract, emission of a toxic pollutant or the extinction of a cherished species.

Case studies of green accounting applied market valuation mostly to natural resource depletion. In the absence of market prices for non-produced natural assets, natural resource rents earned by selling resource outputs in markets are used for estimating the net present value and value changes (notably from depletion) of an asset. For environmental degradation, maintenance costs of avoiding or mitigating environmental impacts can be applied. A few studies used damage valuations of environmental impacts. Such welfare measurement and valuation are characteristic of cost-benefit analyses of projects and programmers; they are not compatible, however, with the market pricing and costing of the national accounts.

\section{Accounting Indicators and Sustainability}

Adding up the rows and columns in Figure 1 generates most of the environmentally adjusted indicators. Net value added and its sum total, net domestic product, can be calculated by deducting intermediate consumption (inputs) and capital consumption from output. Further deduction of environmental depletion and degradation cost obtains Environmentally-adjusted net Value Added (EVA) and Domestic Product (EDP). The popular 'green GDP' accounts only for natural capital consumption, ignoring the depreciation of produced ('fixed') capital. Subtracting both natural and produced capital consumption from capital formation obtains Environmentally-adjusted net Capital Formation (ECF). ECF, in particular, tells us if our economy has been able to generate new capital after taking total capital loss (depletion/consumption) into account. Total capital maintenance represents a weak sustainability concept as it implies substitution among different produced and nonproduced production factors.

Material flow accounts cater to a different sustainability concept. They assess material throughput as an environmental impact or pressure (on carrying capacities) indicator. Dematerialization by reducing throughput to a desirable level is the ecological concept of sustainability. It reflects stronger sustainability, restricting substitution to materials covered by overall material flow indicators such as Total Material Requirement (TMR) or Direct Material Input (DMI).

\section{Policy Uses}

Apart from score keeping, i.e. answering the question whether the economy has performed sustainably during one or more accounting periods, green accounting indicators can be employed in policy formulation and evaluation.

At the macro-level the increase of productive wealth is the key determinant of the economic growth potential of an economy. Especially in resource-rich developing countries, natural resource rents, determined in natural resource accounts, could be absorbed in a development fund. Rather than using the earnings for short-term private and public consumption, these funds should be invested in long-term development projects.

A particular strength of green accounting is the measurement of environmental cost caused by economic agents of households and enterprises. The well-known polluter/user pays principles hold the responsible agents accountable for their environmental impacts. Economists deem market instruments of environmental cost internalization more efficient in bringing about sustainable production and consumption patterns than top-down environmental regulation. In the absence of green accounting information, political exigencies rather than rational cost estimates appear to determine in most cases the setting of market instruments. 
The SEEA accounts explicitly for actual environmental expenditures by different agencies and organizations. Sharing the burden of environmental protection with emerging groups of civil society and private corporations ('public-private partnerships') is one of the key recommendations of the 2002 Johannesburg Summit of the United Nations. Green accounting and accounting analysis can assess the economic and ecological efficiency of different environmental protection measures by governmental and non-governmental organizations.

Whether I decide to be a soccer fan, an opera expert or a religious mystic is not a matter I need to coordinate with others; it is the kind of decision that I can take by myself. Think about it and you will find a large number of others decisions that do not require coordination with other people. Indeed, most decisions regarding consumption are best made by the individual doing the consuming. But when we make decisions regarding what and how we are to produce, very often we benefit from coordinating our activities with those of others.

To explain this process and to elucidate the elemental laws of economics, classical economists used the example of Robinson Crusoe. Like the soccer fan, when Crusoe arrived on his desert island, he needed only to consider the effects of his actions on himself. When Viernes (Man Friday) comes into the picture, however, the situation changes. Crusoe's decisions must now take his new companion into account. Among the good things that can happen is one that Adam Smith viewed as the cornerstone of human progress: the division of labour. This allows for the division of tasks, resources and time and enables each individual to exploit his or her comparative advantage arising from his or her different abilities. Thus, Crusoe gets the food and Viernes the water. And the division of labour brings about better satisfaction of human needs and wants, whatever those may be. (In the case of Crusoe and Viernes, there is now more food and more water for both.)

But in order to enjoy the benefits of this division of labour, the actions of humans must be coordinated. It would be useless for Crusoe to concentrate on obtaining food and for Viernes to do the same with regard to water, unless they are able mutually to benefit from this division of labour. Now the question arises: how should this coordination be achieved?

Actually, the answer to this question is dependent on a previous one: how can such coordination be achieved? (It would be pointless to consider options in response the "should" question if they are nonetheless unachievable.) Two "pure" alternatives that are regularly offered: One was made famous by Adam Smith in The Wealth of Nations as the "invisible hand" of the market. This is a spontaneous order, wherein coordination is based on the voluntary exchange of property among individuals in a free society. The other is based on command and control, on power and social engineering, planning and political decisions. Of course there are many shades of grey in between, but the two main ideas, markets and planning, are always there to different degrees. This is true in many different fields of activity: in morals and culture, in firms and sport teams, in currencies and arts.

One such field in which these alternatives are suggested is natural resources and the environment. This is an area where both consumption and production decisions may have effects on others. As such, it is an area where the actions of human beings require coordination. The question again is: how should this coordination be achieved? Under the conceptual framework previously described, the two options, markets and planning, should be considered and evaluated. This chapter is an attempt to describe such an endeavour. The motive for so doing is that in many instances one option (markets) is usually disregarded in order to consider only different instances of the other (planning). This tendency is exemplified by the initiatives at the United Nations to introduce so-called "green accounting" or, more formally, a system of integrated environmental and economic national accounting.

The problem we face is how to use the planet's natural resources in a sustainable way. In other words, how do we ensure that resources are used in a way that - per the Brundtland Report definition of 'sustainable development' ensures on the one hand that the needs of the present generation are met, whilst on the other ensuring that sufficient resources remain so that future generations are able to meet their needs. ${ }^{1}$

It should be noted, though, that the word "resource" connotes a valuation - a subjective valuation for an individual. The planet is full of "matter", but not all of it is a resource for us, nor is all of it necessary to produce a 'natural equilibrium' (if such a thing ever existed or is even possible). Some of this matter, in excess, can even be a danger for life as one could say of lava or carbon dioxide, for example.

The subjective nature of resource valuation means that in order for resource exploitation to be effectively coordinated, there must even be coordination of the different criteria used to establish what a resource is. That, of course, makes the problem much more complex. If we were in unanimous agreement about what is and what is not a resource, as well as who is entitled to what resources, then co-ordination would merely be a matter of assigning engineers to design the best allocation system. But when something is a resource for some and not for others, or even is a nuisance for a few, something else is required.

Some argue that the solution to this conundrum is better central planning - incorporating more fully all the possible determinants of human desire and happiness. (Although explicit philosophical justification is rarely if ever given, proponents presumably support such central planning on the grounds that it will create the best of all possible worlds maximising human happiness.) Others disagree. Again we come back to the conflict: should decisions be left to individuals acting in the market, or should the planners decide?

\section{Measuring the Unmeasurable}

How do you measure happiness, anyway? This question has 
vexed philosophers, psychologists and economists for centuries without ever leading to a satisfactory answer. In an attempt to overcome the inherently subjective nature of happiness and produce an objective measure of human welfare, neoclassical economists have developed a range of different indexes of economic performance. The presumption behind this approach is that a higher level of economic development means a better satisfaction of human needs. Since its invention by Simon Kuznets in the 1940s (and subsequent adoption by the UN), Gross National Product (GNP) has reigned supreme as an indicator for the economic performance of a country. As Herman Kahn points out:

Even many who accept the desirability of economic affluence and technological achievement have qualms about using the common measure of such progress -GNP (gross national product) per capita. Indeed, almost any explicit use of this index has become discredited in some academic and intellectual circles. Explicit is emphasized because, despite its many theoretical and practical defects, practically everybody includes GNP per capita in any serious judgment about a nation's economic affluence, technological advancement, and ability to produce for culturally desirable purposes.

Furthermore, governments everywhere try to increase it. Even the zero-growth movement uses the GNP concept, if only negatively ${ }^{1}$.

Though there have been critics of GNP as a measurement of progress, such criticism has focused on the form - not the fundamentals - of the concept. Recently, the focus has been on 'greening' the national accounts by adding factors representing such things as the depletion of the natural capital stock. According to a recent United Nations Environment Programme (UNEP) report:

Green accounting addresses the shortcoming of traditional national accounting, known as the System of National Accounts (SNA). Green accounting is based on the concept that a proper assessment of a country's income and wealth needs to account for the contributions of activities made by all sectors of the economy and their impact on resource depletion and degradation. Traditional SNA ignores the value of resources (on and in the ground) as well as the value of environmental degradation. Therefore, it gives a false impression of income and wealth and often leads policymakers to ignore or destroy the environment to further economic development. Incorporating the real value of natural resources as well as their depletion and degradation allows for better allocation of priorities, thereby helping to address the causes of current major environmental problems including the over-exploitation of natural resources such as forests. ${ }^{2}$

Such adjustments hardly represent a revolution. Indeed, they do little more than tinker at the edges with a very dubious idea - which for years was the preferred tool to implement vain and failed attempts to plan the economy. As the ecologist Hazel Henderson says:

Historical and current evaluation tools used to measure

\footnotetext{
1 - Kahn (1979), p.53.
}

2 - UNEP (1997). industrial 'success', deeply rooted in macroeconomic models, are now obsolete from perspectives of global equity and human development, as well as those of the global environment and resource management. ${ }^{3}$

Since Earth Day 1970, environmentalists have challenged economists' definitions of progress, wealth, and development pointing out that economic theories and models short-change Nature as well as future generations. They highlight absurdities of GNP accounting such as in Alaska, which posted gains after the Exxon Valdez oil spill because the additional costs of the clean-up are added to GNP instead of being subtracted (as environmentalists advocate). GNP ignores the value of clear water, fish and pristine, scenic environments like Prince William Sound."4

The author quotes The Economist: Conventional statistics of economic growth are... particularly blind to the environment. National income accounts (Gross National Product) take no notice of the value of natural resources: a country that cut down all its trees, sold them as wood chips and gambles away the money... would appear from its national accounts to have got richer in terms of GNP per person. Equally, they show measures to tackle pollution as bonuses, not burdens... It would be easier for politicians to talk rationally about effects of sensible environmental policies on growth if governments agreed to remove some of these oddities from the way they keep their economic books. ${ }^{5}$

Starting in the 60 s there have been several attempts to create new indexes, measuring such quantities as "Basic Human Needs" or "Material Quality of Life" or the "Measure of Economic Welfare" (developed by economists James Tobin and William Nordhaus). In 1989, the president of Venezuela organized a meeting entitled "Towards New Ways to Measure Development," which recommended including the degree of literacy or life expectations. Likewise, the OECD has developed its Environmental Indicators to complement the information in national accounts. ${ }^{7}$ In May 1989 the OECD Council called for the development of a means of integrating the process of economic and environmental decision-making. This concept was supported at the G-7 summit meeting in Paris in July of the same year. The G-7 meeting in July of the following year declared, "we encourage the OECD to speed up its most useful work on the economy and the environment. Of particular importance is the development of environmental indicators and the design of market approaches to be used in order to achieve environmental goals". Nevertheless, the OECD-designed indicators are far from the planning ambitions of the UN.

\section{Green National Accounting}

The most developed and complete attempt at an alternative to national accounts - and the one with the highest likelihood of being implemented - is, no doubt, the one developed by the

\footnotetext{
3 - Henderson (1991), p. 29

4 - Henderson (1991), p. 202

5 - Henderson (1991), p. 75. OECD (1991).
} 
UN under the name 'Integrated System of Environmental and Economic Accounts' (IEEA), which originated at a series of seminars organized by the UNEP and the World Bank during the 1980 s.

The IEEA originated at a series of seminars organised by the UNEP and the World Bank during the 1980s. At these seminars, two main approaches were considered: The first was to create separate "satellite" accounts alongside the traditional national accounts, to capture changes in natural resources but not to integrate them within the framework of the traditional SNA. The other is to integrate the measures with the traditional SNA - although this would be limited to easily valued resources (such as oil, coal and timber) and would not include other environmental aspects, such as pollution.

During the 1990s, some Latin American countries such as Colombia and Mexico experimented with IEEA, although in parallel to the traditional SNA. The UN expectations are that it might eventually replace the SNA altogether.

From the green accounting of the IEEA it is expected that new indicators will be developed to replace the traditional GNP or GDP. One such is the Eco-Domestic Product (EDP), under which certain activities - such as the extraction and export of minerals - would be accounted for differently than they are under GDP/GNP. So, for example, in conventional national accounting, when a country increases its exports of minerals it counts as an increase of GDP. By contrast, under EDP, the decline in the stock of natural resources would show up as a negative figure, reducing the gain from the production and export of the mineral.

The UNEP report says such an indicator "would serve as an aid to policy setting and enable more informed decisionmaking regarding resource allocation and economic development". But decision-making by whom? Not the mineral companies making investment decisions - they already know their cost of capital and are able to evaluate individual projects based on the likely flow of revenues. No, UNEP means decision-making by government. Government officials would use the information to impose restrictions on the activities of private individuals and companies. For example, they might restrict the production of a specific mineral through taxation or quotas.

One problem with EDP is that it amounts to double counting. When a company buys a piece of land, which it believes to contain mineral deposits, the cost of that purchase shows as an expenditure on the company accounts. In order to make the purchase, the company will use resources that could have been deployed elsewhere. The investment will therefore affect the profitability of the company. If it is a good investment it will increase profits - and hence show as an increase in GDP. If it is a bad investment it will reduce profits - and hence show as a reduction in GDP. Either way the cost of the investment already shows on GDP, so to include separately the depletion of the mineral reserves that result from exploiting the investment amounts to counting that depletion twice: once as the amortized cost of capital associated with the purchase, and again as a reduction in the stock of resources.

Because EDP double counts the sunk costs of capital investment, such restrictions would amount to double taxation of mineral extraction. The result would be an increase in the cost of minerals and all the downstream activities that are reliant upon them. Economic actors would, perversely, be encouraged to substitute non-mineral resources. So, oil from fish and other marine animals might be used in place of crude oil, encouraging more rapid depletion of these species. Of course, environmentalists might argue that fish and whales should also be included in EDP, in which case the effect on consumption of each resource would depend on the level of restrictions (quotas, taxes) attached to each, as well as their substitutability.

If all natural resources were taxed, there would be a bias in favour of using human labour as a substitute. So, instead of using chemical pesticides (including so-called 'organic' pesticides such as copper sulphate and bacillus thuringiensis), which require the use of natural resources, there would be an incentive to go back to manual removal of insects and weeds. Miners would be made unemployed but some would obtain jobs as manual labourers on farms. The number of lowvalue-added activities, such as weeding, would increase. Meanwhile, the number of high value-added activities, such as identifying and developing new medicines capable of reducing child mortality, would decrease. Generally speaking, the economic effect of implementing EDP would be negative.

This leads to something of a paradox: EDP is justified on the grounds that it will increase overall human satisfaction and well-being. But inasmuch as human satisfaction is more dependant on the actual level of economic activity than on the amount of natural resources remaining (either in an individual country or on the Earth as a whole), the immediate result of implementing EDP will be to reduce human satisfaction and well-being.

EDP would also be constrained by the fact that it is dependant on a static conceptualization of what is a resource. In reality, the nature of resources changes over time. During the $19^{\text {th }}$ century, whale oil was an important fuel, especially for lighting, and an entire industry grew up around the hunting and processing of oil-rich whales, such as Blues and Greys. So large was this industry that it threatened to wipe out the entire population of these magnificent creatures. ${ }^{6}$ When crude oil was discovered and methods for extracting and refining it developed, it largely replaced whale oil, saving these whales from extinction. In rich countries, oil has been replaced by distributed electricity as the dominant source of energy for lighting, though oil remains important in this context in poor countries.

What would have happened if, on the grounds that oil is a depletable resource, the US had regulated the use of US crude oil reserves at the end of the $19^{\text {th }}$ century - imposing a hefty tax on it, for example? The cost of using paraffin derived from crude oil would have been high compared to whale oil, so the hunt for whales would have continued for longer

6 - Davis et al. (1997). 
before finally ceasing. Almost certainly numbers of Blues and Greys would be lower than they are today. (This presumes that the US would not have attempted to impose restrictions on the hunting of whales outside its territorial boundaries.)

In addition, the cost of other refined products, such as octane and diesel, would have been high compared to other countries, so discouraging their use as a fuel for transport. This would have discouraged the development of the US automobile industry. Perhaps Henry Ford would never have invented the automobile production line. For transport, people would have relied for longer on horses, which would have continued to foul the streets in greater quantities. Generally things would have been slower and less efficient.

If similar restrictions had been placed on the use of crude oil by countries around the world, economic growth in the past century would certainly have been slower than it has been and the toll on human life would have been great. Of course, opponents of modern civilization will argue that without oil, the two world wars might never have taken place, or that they would have been less severe. But consider another counterfactual: Perhaps, in the absence of abundant, cheap gasoline, the drive to produce nuclear power would have been more intense and less concern placed on the adverse consequences. Germany might have won the Second World War by detonating atom bombs over New York and Washington DC. Of course, all of this is a flight of fancy, but it is not entirely far fetched. Ideas have consequences and this particular idea might have had many negative consequences.

In their bid to construct a system of green national accounts, officials have so far mostly addressed resources, such as minerals, for which there are established markets and visible prices. Those prices fulfil a very important role: they are indicators of the future availability and the future valuation of a resource. They also create incentives to act on that information. If one resource is being replaced by another or its supply is increasing, its price will be falling, increasing the incentive to consume it. If, on the other hand, demand for a resource is increasing or its supply falling, its price will be rising, reducing the incentive to consume it and creating incentives to find and develop alternative resources. Many decisions will be made on the basis of such information, with some people speculating a future scarcity, others a future surplus, and losers learning from winners as they compare their profits and losses.

The price system, as Friedrich Hayek showed, ${ }^{7}$ relays information not only on the physical availability of a resource but, more importantly, about the valuation consumers and producers make about it.

It is true, as the UN report observes, that in some countries "traditional SNA ignores the value of resources (on and in the ground) as well as the value of environmental degradation" giving a "false impression of income and wealth." And as the UN says "incorporating the real value of

7 - Hayek (1937; 1945). natural resources as well as their depletion and degradation allows for better allocation of priorities, thereby helping to address the causes of current major environmental problems including the over-exploitation of natural resources such as forests". But that is a task government officials cannot do because they cannot know the valuations placed on these things by individuals. By contrast, such valuations can be expressed through markets: where there are clearly defined property rights and people are free to contract for the purchase and sale of such rights, individuals express their valuations through their choices about what to buy and sell. And the SNA incorporates the subsequent choices.

\section{Accounting Without Prices}

Prices arise from free exchanges of property between two parties. That is, a price is the ratio of exchange between two owned things. Therefore the existence of prices requires two things: (1) freedom to make contracts for those exchanges and (2) property rights that may be legally enforceable. The absence of either requirement precludes the existence of a price system.

In the absence of prices we are faced with two possibilities, which again shows the planning versus markets dilemma. The "market" solution is to remove the barriers to exchanges and allow for the creation of property rights. Prices will then emerge, acting as a guide to individuals' choices with regard to the future uses of resources.

Some may show concern about the decisions individuals make and demand an alternative "planning" solution. But government officials are individuals as well and can make the same - and worse - mistakes. At least property owners are rewarded if they make proper use of a resource, taking care of it or multiplying it, and are punished if they do not. Government officials, in contrast, rarely suffer personally for the losses their decisions bring about.

In order to try to make "planning" more effective, people have searched for replacements to prices that may give government officials appropriate information on which to base decisions. It is this second option that is being pursued by the UNEP. But new and insurmountable problems are created.

First of all, a physical accounting is needed, but that is no small endeavour. This is what the UN says:

Nature is composed of biological assets (produced and wild), water and soil surfaces with their ecosystems, underground assets and air. Attention must be paid to living beings (animals and plants) and their natural environment. Therefore, all animals and plants associated with the natural environment and their living conditions should be supervised. Including cattle and other animals controlled by man, as well as wild animals, agricultural plants and trees as well as wild ones. $^{8}$

It is immediately clear that the task for the "environmental accountant" is unachievable. First, we do not know - even

8 - UN (1994), p. 8. 
within an order of magnitude - how many species of plant and animal there are on the planet, let alone how many there are of individual species, nor by inference their rate of depletion. ${ }^{9}$ Physical accounting then looks like an idea that may rapidly become ridiculous: Should all doves be counted? And what about their stock changes from year to year? What about cockroaches? Are they a "resource" to be counted or should GDP accounts include the production of "roach killers" instead? This last example shows the need to incorporate valuations into the accounting process. But then, how will be the connection between physical units and the valuations of individuals made?

As we have already noted, consumers reveal their preferences through their decisions to buy and sell. Perhaps inspired by this fact, one of the first proposals by the UN was to poll consumers, asking them how much money they would be willing to spend on various en vironmental amenities:

A direct valuation of benefits (or losses) related to the economic functions of the environment is usually only possible asking people about the monetary value of those functions. This method (contingent or conditional valuation) starts from the assumption that those polled have enough information with regard to the benefits in monetary terms. ${ }^{10}$

The UN's proposal also includes the use of data related to the cost of pollution or the expenditures needed to comply with certain regulations. As an example of the first case it is mentioned "...the valuation of a reduction in air quality. Each person could be asked what annual amount would be willing to pay in order to avoid such a change in quality."11

The UN explains that the method used for estimating the costs for non-market goods was contingent valuation by applying the willingness-to-pay approach. Here consumers were asked how much they were prepared to pay for a better or healthier environment. Another approach was to use a questionnaire, where people were asked to what extent they would reduce their consumption in order to achieve fewer environmental hazards. ${ }^{12}$

But there is a big difference between a decision in the marketplace and an opinion given to a pollster. When someone buys or sells in a market, the transaction has a direct cost to the decision-maker as well as an opportunity cost in the form of the alternative decisions that could have been made. No such costs are associated with a poll; just giving an answer to a questioner has no cost, direct or opportunity. Anyone can see the difference between answering a request about how much money one would be willing to pay to have clean air and actually issuing a check for that same amount. ${ }^{13}$

9 - Estimates vary from as few as 3 million to as many as 110 million species (see Adler, this volume).

10 - UN (1994), Ch. 5.

11 - Ibid, p. 18.

12 - UNEP (1994)

13 - There is in fact a huge literature on what is known as the 'contingent

valuation method' (CVM). The

interested reader is directed in particular to Kahnemann et al. (1990), Harrison

(1992), Hanemann (1994) and Coursey (1998). This literature suggests that well-

designed CVM studies provide a rank ordering of the public's willingness to pay
Other environmentalists even try to go beyond this. Ecologist Hazel Henderson says that "the data on externalities and social costs would have to be developed by more realistic disciplines: thermodynamics, biology, systems and chaos models and ecology." ${ }^{14}$ Actually, this approach would almost guarantee complete "chaos" in the management of resources.

In Argentina, the Fundación Vida Silvestre (Wildlife Foundation) supports a "political criteria":

"A new methodology needs to be created in order to value natural resources and its contribution to the economy. In such a valuation process government agencies, scientific institutions, universities and NGOs should participate." 15

But one can only imagine the degree of political activity and lobbying that such a proposal would bring. Ironically, the supporters of EDP emphasize the importance of political activity, implying that this will be a positive force:

"Tremendous political activity on the part of the 'global citizens of every nation will be needed to force these priorities onto politicians and other leaders in business and academe, unions, and other social groups. The more we have better social and economic indicators to provide better feedback on our current course, the sooner political will can be mustered for the necessary shift in policies."

No wonder they are having trouble constructing a reliable green accounting system. The Chief of Division for InputOutput Analyses at Germany's Federal Statistical Office is quoted as saying that "it was easy to develop concepts, but difficult to implement them...Focusing on the most important environmental problems caused certain difficulties, since it was not easy to make a list of priorities. It was possible that some problems were not recognized because they were thought to be minor, but under closer scrutiny it transpired that, they could cause major monetary losses" (UNEP, op. cit, p.2)

In the end, the problems stems from the intention to plan the activities of people. Again, as Hayek has said, it is not a matter of the existence of planning or not but a question of who does the planning: government officials with the difficulties they find or individuals guided by the price system which makes use of widely dispersed information of such a kind that it may not even be available in a form that my allow its transfer to government decision-makers.

To the proponents of EDP, society is something that needs to be guided by a central planner. And planners need feedback in order effectively to implement their plan; hence the need to develop instruments such as green accounting. Hazel Henderson reiterates this idea quite clearly:

"In fact, trying to run a complex society on a single indicator like the Gross National Product is literally like trying to fly a 747 with only one gauge on the instrument panel. There would be nothing there to tell you whether the wing flaps were up or down, whether the fuel tank was full

\footnotetext{
for specific environmental or public goods but not much more

14 - Henderson (1991), p. 270.

15 - Fundación Vida Silvestre (1993), p. 41.

16 - Henderson (1991), p. 79
} 
or what the altitude was. In effect, you'd be flying blind. Or imagine if your doctor, when giving you a check up, did no more than check your blood pressure!" (p.128)

The problem with this perspective, however, is that society is nothing like a jetliner, with its unique destination and clear need for a pilot. A society is composed of hundreds of thousands, or indeed millions, of individuals, each one of them unique, with different needs, wishes and capabilities and, therefore, with different destinations. Actually, a free society resembles more the entire transportation system, where people can choose not only the destination, but also the time of departure and the mode of transport.

\section{Extending the Market}

The lack of property rights and the consequent lack of prices for the natural assets not only causes problems for green accountants, it also results in what is called "the tragedy of the commons" 17 - or perhaps more accurately, the tragedy of open access. This is a situation that arises when there is no clear assignment of benefits and costs to individual users of a resource. As a result, each user has an incentive to use as much of the resource as possible. When the resource becomes scarce (which might happen, for example, when the number of users increases or when technology reduces the private cost of exploitation), depletion occurs because the benefits of exploitation are private whilst the costs are shared with all the other users.

By contrast, the owners of property rights become "protectors" of the assets they own. But in order for such a right to exist there must be possible to exclude non-owners from its use, and its predation.

The history of Argentina shows a clear example of this. Spanish explorers brought horses and cows to the now famous "pampas" and in this favourable environment, large numbers of wild herds of these animals grew - until one of the first local industries was established: leather. Tanneries were set up and animals were chased and killed over the pampas for their skin alone, leaving the remains to be consumed by predators.

In this situation of open access, cattle were being killed by predators at such a rate that in the early the nineteenth century, in an attempt to save the endangered species, Viceroy Arredondo tried to control the tanneries. Historian Félix de Azara estimates there were 48 million head of cattle in the Pampas in 1700 but by 1800 only 6 million remained. ${ }^{20}$ The lack of property over cattle did not allow for the existence of "protectors" - someone who would not only try to get leather from cattle but also would have an incentive to encourage the animals to reproduce and thereby ensure a future supply. Establishing property rights faced some difficult problems: cattle is a moving resource, so even if the borders between different pieces of land could have been clearly marked, the cattle would not have respected them. However, with the introduction of barbed wire, property rights

17 - Hardin (1968). in cattle could be enforced and cattle ceased to be an endangered species in Argentina. Actually, the idea that cows could be an endangered species would now make many argentines laugh, probably not knowing such was the case 200 years ago.

Once property rights are established, the benefits and costs of managing a resource fall with the owner who, therefore, has an incentive to protect her resources in order to preserve and enhance their value. Of course, property rights do not eliminate error from decision-making, but they do bring a powerful motivation to learn from past mistakes. If owners do not learn from their mistakes and those of others, the resource may decline in value, or they may lose control of it. Also, because owners can enforce their rights through the courts, they do not need tremendous political action in order to act. Political and other collective actions suffer from "freerider" problems, making them difficult and costly. By contrast, the courts are typically cheaper and quicker, so using them rather than the political process reduces the cost of acting and increases the likelihood that decisions will be made in a timely and effective manner.

True, setting up property rights over some kinds of resources is not an easy matter - whales and the atmosphere spring to mind. But the creativity of humans should not be underestimated: we are now able to farm almost any kind of animal, from crocodiles to shrimp, and those that cannot be farmed, such as elephants, can be raised in protected en vironments.

One only has to look at the small rivers traversing the city of Buenos Aires, or even the large Rio de la Plata, to see that its present owner, the government, is not a good protector. Several are so polluted that no creatures are able to survive in them. All are so polluted that it is unsafe for city dwellers to bathe in them during the long, hot summer. To the casual observer, it seems difficult to assign property rights to courses of water. But there are already several examples of such systems in common law countries. In the Western USA, where water is very scarce, rights to water were apportioned on a first-in-time basis. As a result, private owners value and hence conserve scarce water supplies. Meanwhile, in England and Wales, riparian owners are entitled to water that is of undiminished quality and so are able to sue polluters. Anglers in the UK, who value water quality because of its impact on the fish they prize, have taken thousands of actions against polluters and thereby kept the rivers far cleaner than otherwise they would have been. ${ }^{18}$ Actually, Argentinean property rights legislation does allow private ownership of small ponds of water, as long as they are part of a single property. Clearly, it would not be difficult to allow riparian owners to enjoy property rights over streams and rivers. Such rights would allow them to act in defence of the resource, something that can now only be done through the political system.

Argentine authorities complain that the different uses of water make it difficult to plan the use of the resource. But it

18 - Quoted in Brailovsky and Foguelman (1991). Bate (2001). 
is this very plurality of interests that make the property rights approach interesting. Say Terry Anderson and Don Leal: ${ }^{19}$

"If all polluters who use an estuary for waste disposal are held strictly liable for the cost of their pollution, they have an incentive to consider the costs and benefits of their actions. Under these circumstances, the market process, with liability enforced by the courts, forces polluters to weigh the costs of abating pollution against the potential damage costs. If it is less expensive to abate pollution than to face the liability, then polluters will do so; if it is not, the other asset owners will be compensated. Of course, this assumes that polluters can be identified and that damages can be assessed, but these are the same assumptions that are necessary if government regulations or fines are to effectively control pollution".

Of course there will be situations where there is a large number of polluters or parties who have been affected by pollution, which would make it difficult to assign responsibilities. But even then there are already some interesting experiences with market-like arrangements, such as tradable pollution permits, which have been shown to be more efficient than traditional regulations - leading to more rapid environmental improvement at lower cost. ${ }^{20}$ Meanwhile, tort law remains open to all other instances where the polluter can be identified (with tracing technologies extending the possibilities of assigning responsibilities).

\section{Conclusions}

Central planning has been extensively tested during the $20^{\text {th }}$ century and has consistently failed to produce economic benefits. ${ }^{21}$ Attempts to make central planning function more effectively by accounting for inputs and outputs made little difference to the effectiveness of Soviet and other systems. So what reason do we have to believe that green national accounts will make central planning of the environment any mor effective?

Curiously enough, the recipe for green accounting and environmental planning does not come from old-fashioned socialist writers but from the very heart of mainstream neoclassical economics. The argument is advanced following what is called "market failure theory" and the supposed inability of market institutions to solve problems that have the characteristics of "public goods", or in this case, bads.

There is not space in this chapter to discuss the detail of the neoclassical theory of market failure. But it is worth considering the case of the lighthouse. Paul Samuelson, in his influential textbook on economics, gave the lighthouse as the classic example of a public good. Lighthouses, it was suggested, would not be supplied privately because there was no means by which the owners could be compensated for the supply of the beneficial warning light they give to ships. However, Ronald Coase, in his seminal article on the subject in the Journal of Law and Economics, pointed out that in

\footnotetext{
19 - Anderson and Leal (1991), p. 139.

20 - Foster and Hahn (1995)

21 - See Steele (this volume)
}

England, lighthouses had been run privately for over a century, the owners earning their keep from a toll charged at ports. ${ }^{22}$ Thus it is clear that public goods can be supplied privately - if only one has the imagination to construct the appropriate institutions.

Suffice it to say that after the disastrous results of economic planning in the former socialist countries and the existing developing ones, the burden of proof should lie on the planners to show they can outperform property rights, markets and the rule of law in the protection of the environment. And while they do that, it would not be a bad idea if they were to redirect all the efforts and budgets currently dedicated to green accounting towards the analysis of ways to develop property rights where they currently do not exist.

\section{References}

[1] Bartelmus, P., 2001. Accounting for sustainability: greening the national accounts, in: M.K. Tolba (Editor), Our Fragile World, Forerunner to the Encyclopedia of Life Support Systems, vol. II. Eolss Publishers, Oxford, pp. 1721-1735

[2] Bartelmus, P. and Seifert, E.K. (Editors), 2003. Green Accounting. Ashgate, Aldershot, UK and Burlington, VT.

[3] Eurostat, 2001. Economy-wide Material Flow Accounts and Derived Indicators, A Methodological Guide. Official Publications of the European Communities, Luxembourg.

[4] United Nations, 1993. Integrated Environmental and Economic Accounting. United Nations, New York (sales no. E.93.XVII.12).

[5] United Nations et al., 1993. System of National Accounts 1993. United Nations, New York and others (sales no. E.94.XVII.4)

[6] United Nations et al., in prep. Environmental and Economic Accounting. United Nations and others, New York and others.

[7] Uno, K. and Bartelmus, P. (Editors), 1998. Environmental Accounting in Theory and Practice. Kluwer Academic Publishers, Dordrecht, Boston and London.

[8] Bartelmus, P., 2008. Quantitative Eco-nomics, How Sustainable Are Our Economies? Springer Science and Business Media, Secaucus, NJ and Heidelberg.

[9] Ecological Economics, 2007. Special issue on Environmental Accounting: Introducing the System of Integrated Environmental and Economic Accounting 2003 - SEE-2003, vol. 61, 589-724.

[10] Anderson T. \& Leal, D. R. (1991), Free Market Environmentalism, San Francisco: Pacific Research Institute for Public Policy.

[11] Bate, R (2001): Saving Our Streams: London: Institute of Economic Affairs. Coase, R. H. (1974) "The Lighthouse in Economics", Journal of Law \& Economics 17, pp. 357-76

[12] Brailovsky, Antonio Elio \& Foguelman Dina (1991) Memoria Verde: Historia Ecológica de la Argentina, Buenos Aires: Ed. Sudamericana.

22 - Coase (1974) 
[13] Coursey, D. (1998) "The revealed demand for a public good: evidence from endangered and threatened species," Symposium on Endangered Species Act, New York University Environmental Law Journal 6, 411-449.

[14] Davis, Lance E. Robert E. Gallman and Karen Gleiter (1997), In Pursuit of Leviathan: Technology, Institutions, Productivity and Profits in American Whaling, 1816 - 1906. Chicago: University of Chicago Press.

[15] Fundación Vida Silvestre (1993), "Situación Ambiental de la Argentina: Recomendaciones yprioridades de acción", Boletín Técnico No 14 Foster, V. and R. W. Hahn (1995). "Designing More Efficient Markets: Lessons from Los. 